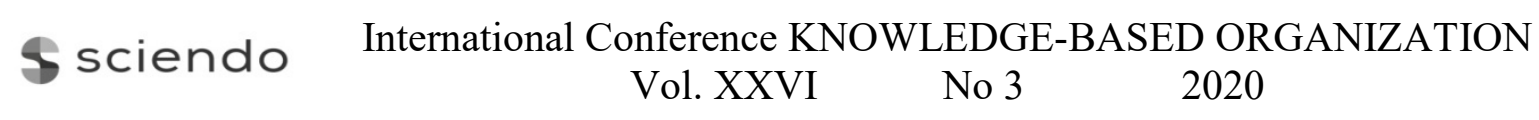

\title{
STRENGTH CALCULATION OF SHELL COMPONENTS OF THE 120-mm MULTIPLE USE SHORT-RANGE TRAINING MORTAR AMMUNITION
}

\author{
Krasimir KALEV \\ "Vasil Levski” National Military University, Veliko Tarnovo, Bulgaria \\ kraskalev@abv.bg
}

\begin{abstract}
In this paper is presented the shell components of Bulgarian 120-mm multiple use shortrange training mortar ammunition. These components are constructed and added to the shell of a 120$\mathrm{mm}$ high explosive mortar round. Thus, with minimal financial resources, the 120-mm multiple use shell were designed and constructed so as to be trained recruits in firing the mortar. Strength calculation of the new shell parts of the 120-mm short-range ammunition has been completed. The largest axial stresses that have arisen in the smoke cartridge during a shot have been calculated in order to prevent the self-ignition of the charge.
\end{abstract}

\section{Keywords: ammunition, short-range training, multiple use shell}

\section{Introduction}

The exercise activities of the mortar crew are at the heart of training and maintaining the high professional skills and habits of individual servicemen [6, 10]. For field combat firing with a $120-\mathrm{mm}$ mortar, the necessary field conditions are required, such as separate areas remote from settlements and the location of military formations, equipped with facilities and additional personnel to ensure firing and security of the firing range. To optimize the preparation of mortar crews, as the trajectory of the mortar shell flight and at a very short distance retains its shape, a variety of $120-\mathrm{mm}$ multiple use short-range mortar ammunition training was created $[16,17]$. In that the initial training of mortar crews, consisting of recruits, helps to more quickly psychologically overcome the effects of mortar shot on the one hand, while reducing the financial cost of ammunition, transporting the crews and $120-\mathrm{mm}$ mortar system to the firing range and other necessary human resources and logistic resources [5] for conducting firing. There are also problems with wear out of mortar barrel [11, 12] and storing large amounts of ammunition [7]. In the artillery round set of $120-\mathrm{mm}$ mortar that are in service in the Bulgarian army there is no multiple use training ammunition.

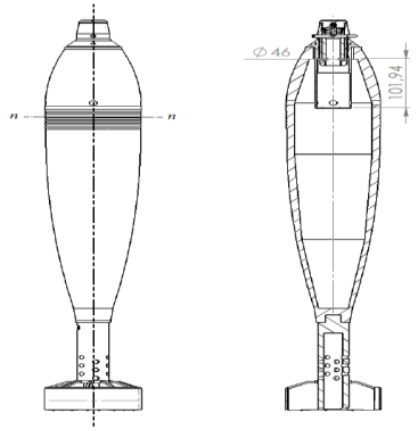

Figure 1: 120-mm multiple use short-range training mortar ammunition

Under a project approved by the Ministry of Defence was developed on the basis of the existing high explosive ammunition a new 120 -mm multiple use short-range training 
mortar ammunition (fig. 1) as used CAD (computer aided design) system $[1,3,8]$. In this paper are exposed the Strength calculations of some new shell parts of the $120 \mathrm{~mm}$ short-range mortar ammunition.

2. Loads on the shell of multiple use short-range mortar ammunition at a shot 2.1. Forces acting on the training shell at a shot

During the phenomenon of shot (from the moment of the resting of the shell in the lower position of the mortar tube, with the subsequent accelerating motion in the barrel until the effect of the powder gases), forces are exerted on the shell body and the shell body details: the exhaust powder gas pressure; the mass of the shell; the reaction of the cannon tube wall and the friction between mortar shell and mortar cannon tube [15].

The exhaust powder gas pressure creates the highest load on the shell body, which is largely determined by the loading conditions. Since the shell of a $120-\mathrm{mm}$ high explosive mortar round from the 120$\mathrm{mm}$ mortar ammunition is used for the training mortar shell, one of the parameters of the loading condition (1) [13, 14], namely the volume of the loading chamber, will have the same value, as with high explosive mortar round

$\Delta=\frac{m}{W_{0}}$,

where $m$ - mass of the shell, $k g$; $W_{0}-$ charging chamber volume, $m^{2}$.

The second parameter of the training shell mass will be slightly different as the high explosive shell is used, the difference being due to the absence of the bursting high explosive charge but whose mass is offset by the addition of new shell elements such as smoke cartridge with a burst imitation charge and a new fuse. The third parameter, the mass of the combat charge is less than that of the high explosive round firing due to the fact that the firing distance of the training shell is significantly less. It also plays a decisive role in the formation and rate of increase of the amount of powder gases in the mortar charger chamber. Under these loading conditions, it is obvious that the maximum pressure of powder gases at a shot will be significantly less at times than with high explosive round firing. Since the maximum pressure of powder gases in the charge chamber during a shot is significantly less than that of a high explosive shell firing, and since a high explosive shell is used for training shell, it follows that when firing a training shell stresses and deformations in the shell will also be significantly less than the allowable ones. This naturally eliminates the need for a strength calculation of the training shell, leaving the obligation to calculate only the newly designed details.

Inertial forces are next in importance to the strength of the training shell. They occur in shell and in shell details as a result of the acceleration they receive as they move under the influence of the system forces generated by the pressure of the exhaust gases. According to mechanics, the forces of inertia can be represented as axial, radial and tangential. Since the shell does not rotate, the main inertial force will be the axial force that arises from the accelerated gradual movement of the training shell. Using Newton's second law, provided that the energy of the propellant is used only for the progressive movement of the training shell in mortar cannon barrel, then the equation of motion in function of time $t$ has the form

$m \frac{d V}{d t}=P S$,

where $V$ - shell speed, $\mathrm{m} / \mathrm{s} ; P$ - pressure of the powder gases in in the shell rear space, $\mathrm{N} / \mathrm{m}^{2} ; S$ - cross-sectional area of mortar cannon barrel, $\mathrm{m}^{2}$

or

$a_{t s}=\frac{d V}{d t}=\frac{1}{4} P \pi D^{2} \frac{\mathrm{g}}{\mathrm{m}}$,

where $g$ - acceleration of gravity, $\mathrm{m} / \mathrm{s}^{2} ; D-$ caliber of training shell, $m$.

It follows from (3) that the acceleration of 
the training shell in mortar cannon barrel is determined by the expression

$a_{t s}=\frac{d V}{d t}=\frac{1}{4} P \pi D^{2} \frac{g}{m}$.

Then the axial inertial force in section $n n$ (fig. 1) of the training shell according to the second principle of mechanics is represented by the equation

$F_{t s}=\frac{m_{s}}{g} \frac{d V}{d t}$,

where $m_{s}$-weight of part of training shell above cross section $\mathrm{nn}, \mathrm{kg}$.

After replacement with (4) in (5) final

$F_{t s}=\frac{1}{4} P \pi D^{2} \frac{m_{s}}{m}$.

To clarify the physical process, a parameter called a load factor $[13,14]$ is used, which is defined as the ratio of external forces $\left(F_{t s}\right)$ acting on the training shell and the mass forces or the ratio of the training shell's acceleration to the acceleration of the weight force.

$n=P \pi D^{2} \frac{1}{4 m}$.

Obviously, the load factor depends on the pressure of the powder gases, the calibre and the weight of the training shell. Since, in this case, the last two quantities are constant, $n$ will depend on the magnitude of the pressure of the powder gases. Therefore, when designing training shell details, it is necessary to take into account the design pressure of powder gases, which is higher than the maximum. Then the maximum axial force of inertia in section $n n$, in accordance with expression (7), will be determined by equation

$F_{n}=n m_{s}$.

Again, due to the fact that a high explosive shell is used to make the training shell, and the lower training shell firing load, the effect of inertial forces on only the newly designed parts will be considered.

In the strength calculations, the critical state of the shell and shell parts is determined, which is characterized by the highest values of stresses and deformations. The time at which the critical state is reached is determined and the magnitude of the stresses and deformations that occur is calculated.

\subsection{Stress and strain state of the training shell body and body details at a shot}

When a shot is fired as a result of the pressure created by the exhausted powder gases, the training shell begins to move along the mortar barrel, while its body is experiencing mechanical stresses. The stressed state of the shell body changes and, depending on its position in the barrel, it can be conditionally assumed that it passes through three stages. The first stage involves the moment when the propellant charge is ignited and the maximum pressure of the powder gases is reached, whereby the maximum stresses and deformations in the walls of the shell occur before the centring thickening and the details contained therein. The next stage begins from the moment of maximum pressure buildup in the shell rear space and ends when the centring thickening passes through the muzzle of the tube. And the last stage of the stressed state involves the moment of passing the centring thickening through the muzzle section and the cessation of the effect of powder gases on the flying out shell.

In the training shell body and shell details, generally, major stresses occur in the corresponding normal and conical sections and bending stresses. When designing shell details, the basic load is the result of the axial inertial forces and the formula for calculating the axial stresses in the normal section is of the form $[4,9]$

$\sigma_{t s}=\frac{F_{n}}{S}$.

\section{Designing a smoke cartridge on of the training shell}

The maximum load of a smoke cartridge results from the action of the inertial force, at a time when the pressure of the powder gases reaches the highest values. Therefore, when designing a smoke cartridge, it must be calculated with the maximum value of 
the axial inertial force that is obtained at a shot.

When fired as a result of maximum gunpowder pressure, which causes the movement of the training shell and its own masses of smoke cartridge and smoke charge, an inertial force is raised which generates tensile stresses in the body of the smoke cartridge. We assume that the body of the smoke cartridge is made according to the technical documentation, with the same thickness of the cylindrical wall. In this case, according to fig. 2 , the critical values of stresses and strains will occur in section $n n$. In addition to the dangerous section $n n$, the tensile stress can also break the integrity of the smoke cartridge and in the section near the bottom, where four openings are drilled in the cylindrical wall of the cup.

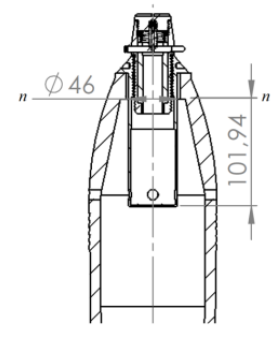

Figure 2

According to item 2 and fig. 2 axial inertial force for smoke cartridge in section $n n$ will be of the form

$F_{c n}=n\left(m_{c n}+J\right)$,

where $m_{s n}$ - weight of part of smoke cartridge above cross section $n n, k g ; J-$ weight of part of smoke charge, $\mathrm{kg}$.

Substituting in (10) the expression (7) for the axial force we have finite

$F_{c n}=P \pi D^{2} \frac{\left(m_{c n}+J\right)}{4 m}$.

The cross-sectional area along the line $n n$

$S_{c n}=\frac{1}{4} \pi\left(D_{n}^{2}-d_{n}^{2}\right)$,

where $D_{n}$ - outer diameter of the smoke cartridge in section $n n, m m ; d_{n}$ - inside diameter of the smoke cartridge in section $\mathrm{nn}, \mathrm{mm}$.

It follows from formula (9) that the tensile stress values will be determined by

$\sigma_{t s n}=\frac{F_{c n}}{S_{c n}}$.

After replacing in (13) with (11) and (12) for tensile stress, we obtain the equation

$\sigma_{t s n}=P \frac{D^{2}}{\left(D_{n}^{2}-d_{n}^{2}\right)} \cdot \frac{\left(m_{c n}+J\right)}{m}$.

The strength condition is

$\sigma_{t s n} \leq[\sigma]=\frac{\sigma_{y}}{k}$,

where $[\sigma]$ - allowable stress of the steel, MPa; $\sigma_{y}$ - yield strength of the steel of which the smoke cartridge is made, $M P a ; k$ - safety factor.

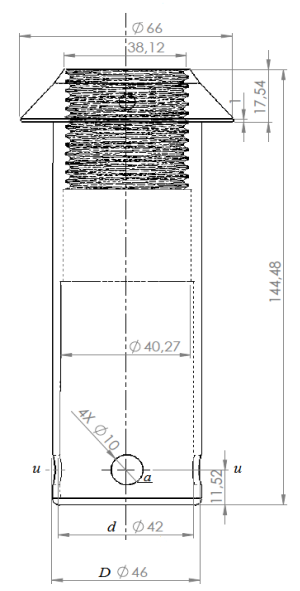

Figure 3: Smoke cartridge

In the cross section $u u$ (fig. 3), due to the four openings, the bearing capacity of the cylindrical wall is weakened and therefore it is necessary to calculate the strength. Since the weight of the smoke charge located below the line $u u$ is small enough to affect the magnitude of the inertial force, it can be neglected. In this case, the inertial force in this section will be determined by the equation

$F_{c u}=P \pi D^{2} \frac{m_{c u}}{4 m}$,

where $m_{s u}$-weight of part of smoke charge below cross section $u u, k g$.

The cross-sectional area along the line $u u$ according to fig. 3 is determined by the formula

$S_{c u}=\frac{1}{4} \pi\left(D_{u}^{2}-d_{u}^{2}\right)-2\left(D_{u}-d_{u}\right) a$, 
where $D_{u}$ - outer diameter of the smoke cartridge in section $u u, m m ; d_{u}$ - inside diameter of the smoke cartridge in section $u u, m m ; a$-diameter of openings in the section $u u, m m$.

Analogous to the above calculation the tensile stress is determined by the expression

$\sigma_{t s u}=\frac{F_{c u}}{S_{c u}}$.

After substituting in (18) for tensile stress, we obtain the equation

$\sigma_{t s u}=P \frac{D^{2} m_{c u}}{\left(D_{u}-d_{u}\right)\left[\left(D_{u}+d_{u}\right)-\frac{8 a}{\pi}\right] G}$.

The strength condition is

$\sigma_{t s u} \leq\left[\sigma_{s u}\right]=\frac{\sigma_{y}}{k}$,

where $[\sigma]$ - allowable stress of the stell, MPa.

The design calculations for the smoke cartridge were made using the following baseline data: $P=34 \mathrm{MPa} ; \quad \mathrm{D}=120 \mathrm{~mm}$; $m=16,2 \mathrm{~kg} ; \quad m_{s}=0,570 \mathrm{~kg} ; \quad m_{s n}=0,210 \mathrm{~kg} ;$ $m_{s u}=0,060 \mathrm{~kg} ; d_{n}=40,27 \mathrm{~mm} ; D_{n}=D_{u}=46 \mathrm{~mm}$; $d_{u}=42 \mathrm{~mm} ; a=10 \mathrm{~mm}$.

After the calculation the $\sigma_{t s n}$ and $\sigma_{t s u}$ and substitution in (15), (20) with the resulting numerical values we obtain the following result

$$
\sigma_{t s u}<[\sigma] \text { and } \sigma_{t s u}<\left[\sigma_{s u}\right] .
$$

Since the calculated maximum stresses in the shell details (the smoke cartridge and in the section near the bottom) are less than the allowable ones, it follows that the designed shell parts will not be destroyed at a shot and will perform their purpose. The strength calculations have completed successfully.

\section{Strength of the training shell charge during a shot}

During the shot, stresses occur not only in the mortar cannon barrel and training shell, but also in the shell smoke charge. These stresses are generated by the inertial forces in the movement of the smoke cartridge in which the smoke charge is placed, and if they exceed the magnitude of the permissible firing stresses, they may cause premature chemical reaction of combustion or detonation. As with the smoke cartridge strength analysis, here the highest load is on the smoke charge axis, therefore the axial inertial force must be used in the calculations.

Based on the reasoning in Section 2.1, it can be assumed that as a result of the axial inertial force that arises in the movement of the training shell, axial stresses in smoke charge appear which can be calculated by the expression (14). Given that the smoke charge is dense and its geometric shape is a cylinder, it can be assumed that the greatest axial stresses are obtained in the section at the bottom of the smoke cartridge, then

$\sigma_{t s s c}=P \frac{D^{2}}{d_{b}^{2}} \cdot \frac{m_{s c}}{m}$,

where $d_{b}$ - diameter of the bottom of the smoke cartridge, $m m ; m_{s c}$ - weight of smoke charge, $\mathrm{kg}$.

The strength condition of the charge is of the form

$\sigma_{t s s c} \leq\left[\sigma_{s c}\right]$,

where $\left[\sigma_{s c}\right]$ - allowable stress of the smoke charge, $M P a$.

The design calculations for the smoke charge were made using the following baseline data: $m_{s c}=0,012 \mathrm{~kg} ; d_{b}=42 \mathrm{~mm}$.

The composition of the charge is of black powder for which $\left[\sigma_{s c}\right]=15 \mathrm{MPa}$. After the calculation, it turns out that the inequality (22) is satisfied, which proves that the charge in the smoke cartridge of the training shell will not be destroyed.

\section{References}

[1] Antonov S., International Scientific Journal „Mathematical Modeling 2018”, Year 2, Issue 4(2018), pp. 156-159, ISSN (PRINT) 2535-0986, ISSN (WEB) 2603-2929, December 2018. 
[2] Genov B. et al., Journal of Acoustics, pp. 13-19, vol. 2013, 2013.

[3] Antonov S., Conev C. G., Possibilities for automation of designing elements of small arms using CAD/CAM/CAE systems distantsii, Collection of papers: Defense and Security, pp. 319-324, Shumen, Bulgaria, ISSN 2367-7902, 2016.

[4] Conev C. G., Konstruktsii na mini za strelba na kysi distantsii, Naucna sesya 2003 Sbornik nauchni trudove - chast I, pp.85, Shumen, Bulgaria, ISSN 954-9681-01-7, 2004.

[5] Dimitrov M. St., Nasoki za razvitie na intermodalnoto transportirane na bojnite pripasi $v$ armiite ot NATO, Nauchna sesiya 2005 Sbornik - chast II, pp. 358-366, Shumen, Bulgaria, ISBN 954-9681-20-3 (ch.2), 2006.

[6] Dimitrov M. St., Penchev R. D., Tendencii za razvitieto na artilerijskite $i$ minohvargachnite sistemy, Nauchna sesiya 2006 Sbornik nauchni trudove - chast II, pp. 295-301, Shumen, Bulgaria, ISBN-13; 978-954-9681-20-8, 2007.

[7] Genov B., Genov G., NATO system for ammunition assessment during their service life, Proceedings of MT\&S conference, pp. III-1, Sofia, Bulgaria, ISBN-978-619-90024-1-4, 8-9 December 2013.

[8] Petrova T., Application of geometrical transformations for the atachment of images to geographical maps, 21st International scientific conference: The teacher of the future, pp. 1917-1922, Skopje, Macedonia, ISSN1857-923X (for e-version), ISSN 2545 4439, 2019.

[9] Petrov N., V. Dimitrov, Forecasting the Technical Resource of the Mechanical and Civil Building Structure, International Journal of Civil Engineering and Technology (IJCIET),(3), ISSN Print: 0976-6308 /ISSN Online: 0976-6316, pp. 173-181, 2016.

[10] Hristov H. A., Conev C. G., Izpolzvane na uchebno-prakticheskite mini v obuchenieto, Naucna sesiya 2011 Sbornik nauchni trudove - chast I, pp.253, Shumen, Bulgaria, ISSN 1313-7433, 2012.

[11] Krasimir G. Kalev, Valentin Z. Topalov, Statistical model of wear in the initial part of the barrel of an automatic firing system, 7 th International Scientific Conference Hemus 2014, pp.157, Sofia, Bulgaria, ISSN 1312-2916, 2014.

[12] Valentin Z. Topalov, Influencing factors upon wearing out of gun barrel during exploitation, Naucna sesiya 2013, pp.189, Shumen, Bulgaria, ISSN 1313-7433, 2014.

[13] Donald E. Carlucci and Sidney S. Jacobson, Theory and Design of Guns and Ammunition, CRC Press, Boca Raton-London-New York, Taylor \& Francis Group, 2014, Page 111-126.

[14] Kuprianov V., Левин D. and Селиванов V., Osnovi proektirovania boeprpasov, Moskva, Izd. MGTU N. E. Bauman, 2019, Page 44-50, 71-90.

[15] Stanag 4110. Definition of pressure terms and their interrelationship for use in the design and proof of cannons or mortars and ammunitions. North Atlantic Treaty Organization, Standardization Agreement.

[16] https://elbitsystems.com/media/Land-Catalog-margemot_22_WEB

[17] https://www.nammo.com/globalassets/pdfs/ammobook/nammo_ammo_handbook 